\title{
Effect of Educational Sessions on Improving Knowledge and Lifestyle among Rural Versus Urban Gestational Diabetic Women \\ Manar D. Mohammed ${ }^{1}$, Magda Fawzy Hasab Allah ${ }^{2}$, Safaa Ali Abdelnaem \\ ${ }^{1}$ Lecturer of Community Health Nursing, ${ }^{2,3}$ Lecturer of Woman Health and Obstetrics Nursing, ${ }^{1,2,3}$ Faculty of Nursing -Minia University.
}

\section{Abstract}

Background: Gestational diabetes mellitus (GDM) is accompanying by possibly risky impacts on the mother and fetus. Therefore, early detection of gestational diabetes mellitus allows enhancing pregnancy consequences and announcing women to suitable nutrition \& lifestyle health promotion. Aim: To evaluate the effect of educational sessions on improving knowledge and lifestyle among rural versus urban gestational diabetic women. Subjects and Method: Design: Quasi-experimental pretest/posttest research design was utilized. Subjects: A purposive sample of 80 women carefully chosen by purposive sampling method as described in inclusion criteria, attended out-patient clinics of Maternal and Child Minia University Hospital, and suffer from GDM. Tools: The data were gathered by using an Arabic structured interviewing sheet including socio-demographic data, knowledge assessment tool, and lifestyle assessment tool. Results: $65.2 \%$ and $70.5 \%$ of both urban and rural groups lacked the essential knowledge regarding GDM in the pretest.82\% and $80 \%$ of them respectively has an unhealthy lifestyle score. However, after the implementation of the educational sessions, it noticed that there was a greatly significant enhancement in their knowledge and healthy lifestyle. Conclusion: There was a statistically significant difference between total knowledge and total lifestyle score, $\mathrm{P}<0.001$ pre and post educational program, so the application of a health educational session plays an important role in improving the knowledge and the lifestyle among women with gestational diabetes in rural and urban areas. Recommendation: Provide a continuous planned educational program and offered on regular basis for both urban and rural groups of women with gestational diabetes to improve their knowledge, the lifestyle and associated morbidity.

Keywords: Gestational diabetes mellitus (GDM), Lifestyle, knowledge. 


\section{Introduction}

Gestational diabetes mellitus (GDM) is a universal health concern, not only because of its higher incidence, but also as a result of the possible complications on mothers and their offspring. GDM was known to be decreased carbohydrate tolerance that arises or is first diagnosed during pregnancy. Thus, GDM is a carbohydrate intolerance that has developed or been discovered for the first-time during pregnancy ${ }^{(1)}$.

Many factors depend on the high prevalence rate of GDM, such as advanced maternal age during pregnancy, obesity, multiple pregnancies, polycystic ovarian syndrome, inadequate sleep and sedentary lifestyle $^{(2)}$. A range of studies focus on the efficacy and effectiveness of educational approaches through educational sessions focused on Health Promotion Lifestyle Profile II (HPLPII) in relation to improving preventive behaviors.In addition, it is assumed that up to 80 percent of diabetes can be avoided with proper preparation, such as enhancing dietary awareness, blood glucose monitoring, maintaining normal glucose levels, reducing the need for insulin, and reducing carbohydrate consumption ${ }^{(3)}$.

Many antepartum, peripartum and postpartum problems are associated with gestational diabetes, such as hypertensi ve disorders, cesarean delivery, dystocia, macrosomia, premature delivery and respiratory distress ${ }^{(4)}$. This also raises the risk of long-term effects in children born to mothers with diabetes, such as persistent glucose resistance and type 2 diabetes, obesity, childhood and adolescent metabolic syndrome ${ }^{(5)}$.

The diagnosis of gestational diabetes mellitus presents an opportunity to enhance the effects of pregnancy and to recognize women for nutritional and lifestyle health promotion. Lifestyle modificationin women with a history of GDM can minimize the risk of developing type 2 diabetes ${ }^{(6)}$.

Lifestyle is one of the key variables that can play an important role in the prevention or treatment of GDM. It is now thought that over 70 percent of diseases are slightly related to the lifestyle of a woman. Gestational diabetes prevention strategies have recently focused on adequate information for promoting healthy lifestyles by encouraging physical activity and promoting healthy balanced $\operatorname{diet}^{(7)}$.

Lifestyle management is the optimal method of dealing with GDM. The theory of healthy nutrition and regulated weight gain is focused on diet. Carbohydrate content within the diet, with a focus on the number, distribution, and form of 
carbohydrates (low glycemic index), is important. Weight assessment and selfmonitoring of blood glucose (BG) levels will monitor the efficacy of the diet. Lowering B.G levels can be improved by exercise. For most women, the most appropriate type of exercise is walking in their regular everyday routine ${ }^{(8)}$.

World Health Organization (WHO) acknowledges the value of antenatal care (ANC) as a continuum of reproductive and maternal-newborn care. Early diagnosis of pregnancy and at least four ANC visits are recommended by the $\mathrm{WHO}$, beginning before 14 weeks of gestation, during which a proposed package of preventive, screening and educational measures is offered $^{(9)}$.

\section{Significance of the study:}

Gestational Diabetic women are at high risk of maternal and neonatal complications, including higherincidence of preeclampsia, cesarean section delivery, prematurity, neonatal macrosomia, hypoglycemia, shoulder dystocia, high perinatal mortality ratio, and admission to the unit of neonatal intensive care ${ }^{(10)}$.

Globally, between 2009 and 2010, the incidence of GDM increased from 8.1 percent to 9.2 percent. The increased risk of having type 2 diabetes and high birth weight for children is the risk of GDM in both mothers and newborns ${ }^{(11)}$. While according to ${ }^{(12,13)}$ the worldwide prevalence of gestational diabetes is between $1 \%$ and $14 \%$. Therefore, this research was carried out to evaluate the effect of educational sessions on improving knowledge and lifestyle among gestational diabetic women. And according to ${ }^{(14)}$. There is a lack of data on the quality of health services offered to gestational diabetic women, a lack of national guidelines on GD screening, management and nursing initiatives to reduce complications and educate pregnant women about self-care steps.

\section{Aim of the study}

To evaluate the effect of educational sessions on improving knowledge and lifestyle among rural versus urban gestational diabetic women.

\section{Research hypothesis}

1) The total scores of post-test knowledge and lifestyle will be significantly improved than the total score of pre-intervention knowledge and lifestyle scores among both groups of women.

2) There will be a significant association between knowledge scores of pregnant women with their healthy lifestyle.

\section{Subjects and Methods}

\section{Research design}

Quasi-experimental research design (pre and post-test) was utilized.

\section{Setting}


The present study was conducted among pregnant women with gestational diabetes mellitus who attended out-patient clinics in Minia Maternal and Child University Hospital.

\section{Subjects}

Apurposive sample was used, (those attending outpatient clinic during the period of our study, who are suffering from GDM).

Sample Size: By using the following formula: $\mathrm{n}=\frac{\left[2\left(\mathrm{z}_{\frac{\alpha}{2}}+\mathrm{Z}_{\beta}\right)^{2} \times \mathbf{p}(\mathbf{1}-\mathbf{p})\right]}{\left(\mathbf{p}_{1}-\mathbf{p}_{2}\right)^{2}}$,

Type of test $=$ two-sided, considering level of significance of $5 \%$, study power of $80 \%$, where $\mathrm{n}=$ sample size required, $\mathrm{p}=$ pooled proportion of event, $p_{1}-p_{2}=$ difference in proportion of event, $Z_{\frac{\alpha}{2}}$ : This depends on level of significance, for $5 \%$ this is $1.96, Z \beta$ : This depends on power, for $80 \%$ this is 0.84 , $n=\frac{\left[2(1.96+0.84)^{2} \times 0.3(1-0.3)\right]}{(0.2)^{2}}=80$. Based on the previously mentioned formula, 80 pregnant women were recruited as (40) women from rural area and (40) women from urban area.

\section{Inclusion Criteria}

Pregnant women with GDM, their age from 18 to 45 years, gestational age from 20 weeks.

\section{Exclusion Criteria}

Pregnant women with other pregnancy complications, having more than single live fetus, women suffer from any medical disorder (DM, hypertension, renal disease, cardiac disease).

\section{Study Tools}

Three tools were used in the present study for data collection

\section{The First Tool(pretest)}

It is an Arabic language structured interviewing sheet developed by the authors. It is consisting of two parts.

Part (I): It includes socio-demographic data: such as (age, residence, educational level, occupation, income, and telephone no).

Part (II): It includes obstetric history of women: e.g. (Gestational age, No of gravidity, No of parity, history of premature baby).

\section{The Second Tool: Knowledge}

\section{Assessment tool (pre/post)}

It is an Arabic language structured interviewing sheet developed by the authors to assess women's knowledge regarding GDM that contains (15) questions MCQ about(definition, risk factors, Consequences, treatment and management, postpartum follow up). Scoring system: knowledge questions were assumed scores (zero, 1 or 2). It was consigned to each answer representing (poor, average, good) respectively. Total 
knowledge score was categorized as poor $(<50 \%)$, average $(50 \%-75 \%)$, good $(>$ $75 \%)$.

\section{The Third Tool: Assessment of Lifestyle} scale (pre/post)

Health Promotion Lifestyle Profile II (HPLPII). It measures the frequency of self-reported healthy behaviors focusing on six main areas including 52 items which focus on physical activity, spiritual growth, health responsibility, interpersonal relations, nutrition, and stress management $^{(15)}$.

\section{Scoring:}

The HPLPII has a Likert-type scale of three points ranging from never (1), sometimes (2), and always (3). The overall health-promoting lifestyle score is a measure of the average response of all items. Subscale scores are calculated using the mean for each set of questions of the subscale. Women' total lifestyle score was classified as the following:

- Unhealthy lifestyle while the total score gave $<60 \%$.

- Healthy lifestyle while the total score from 60 to $100 \%$.

\section{Method}

\section{Validity}

The sheet was provided by five-panel experts from community health \&obstetrics and gynecological department nursing professors who revised the tools for accuracy, relevance, inclusiveness, understanding, applicability and simplicity. Reliability: The test by Alpha Cronbach was conducted to evaluate the steadiness of the instruments' internal consistency. Knowledge sheet was 0.870 . It was 0.852 for the assessment of lifestyle scale, hence the sheets were found to be highly reliable.

\section{Pilot study}

It was carried out on $10 \%$ of the overall sample examined (8 women). It was carried out to assess the applicability and clarity of the instruments, evaluate the feasibility of fieldwork, and identify any potential difficulties that the investigator could encounter and impede the collection of data. Important improvements have been made based on the findings of the pilot study, such as (removing certain questions and adding others) to endorse their content or for clearer and more specific purposes. In the basic sample, the trial sample was involved.

\section{Ethical consideration}

All formal permits were obtained from convenient authorities to perform the report. The relevance and purpose of this study were discussed with the participants. Both participants were told that their contribution was voluntary and their right to discontinue at any time, that data confidentiality was achieved, and that the 
data collected was only used for the purpose of the present study.

\section{The actual study}

A written approval letter was officially obtained from the directors and the head of the department of Obstetrics and Gynecology at Minia Maternal and Child University Hospital, describing the purpose of the current research. The researchers visited the hospital (outpatient clinic) for three days a week from 9:30 a.m. to $12: 30$ p.m. until the predetermined sample size was achieved between the beginning of September 2019 and the end of February 2020.The present study was performed in three phases: assessment phase (pre-test), implementation phase (carrying out education program), followup and evaluation phase (post-test).

\section{Assessment phase (pre-test)}

- The researchers conducting the first meeting in the outpatient clinic with women. And briefly explain the essence and the intent of the study. The women have been told that their contribution and their right to discontinuation at any time are optional. Oral approval from all women was obtained.

- After obtaining the women's agreement to participate in the present study, the researchers explained to each woman an outline and illustration of the evaluation tools issues. Therefore, each participant was given an Arabic standardized interviewing sheet to evaluate socio-demographic characteristics, obstetric history, evaluate their knowledge, and their GDM lifestyle.And for illiterate women, the researchers filled the sheet for them. It took about 25-30 minutes for each woman to complete the questions sheet. Around 3 to 4 women were organized daily by the researchers. At the end of the pretest, an agreement was made with each woman on a suitable date for the implementation of the educational sessions, and ten women who correspond at the same date were assembled (8 groups of women were arranged).

\section{2-Implementation phase (carrying out} education program)

- In implementation phase two educational sessions for theoretical and practical information about gestational diabetes were provided to the group of women based on their agreement on a suitable date for them, each session took about (3035)minutes. At the beginning, the pregnant women were oriented with the educational sessions' contents. In the $1^{\text {st }}$ session, the definition of 
gestational diabetes, causes, risk factors, symptoms, complications \& treatment (medication type \& side effects and proper storage of medications), management (the importance of blood glucose control, training on self-monitoring of blood glucose), and its prevention were discussed. The $2^{\text {nd }}$ session concerned with a discussion of women's lifestyle towards gestational diabetes, effect onwoman's life, discussion of healthy dietaryhabits and nutritional behaviors, number of meals and foods thatcould increase and decrease blood glucoselevel, teachingthe mother selfcare activities that womenshould follow to cope with gestationaldiabetes as safe physical exercises(recommended duration \& type of exercise,adequate rest during exercise and dangersigns during exercise), importance of stress management, health responsibilities, and her spiritual growth to avoid GDM complication.

- Health education was given to the women as a symposium and group discussion by using instructional material on health education at a separate room in the hospital, it emphasized improving women's knowledge and a healthy lifestyle in copingwith gestational diabetes. At the finishing of the symposium, feedback from the women about the topic was obtained to ensure the ultimate benefits for women were obtained.

- Handbook covering information about GDM was given to women at the ending of the sessions to achieve its objectives. It consists of significant information about GDM (concept, reasons, risk factors, clinical picture, investigation, consequences, treatment, and its prevention in addition to the role of a healthy lifestyle to cope with GDM and decrease the complication of it). Also, the investigators contacted women via telephone call for following up and supporting.

\section{Follow up and evaluation phase} (post-test):

- Follow-up and evaluation phase were conducted during her antenatal follow-up (after four weeks) from the implementation of educational program to detect her commitment to educational intervention instructions. (Follow-up post-test), in this phase, the researchers noticed that there are some barriers that hider the commitment of women to change their lifestyle were covered, but the 
researchers re-stressed on the other barriers to ensure their complete commitment to an educational program and effectiveness of it.

- The influence of the educational sessions on improving knowledge and lifestyle was achieved through a preand post-test comparison that was carried out after four weeks of intervention to determine their GDM knowledge and lifestyle. The data was collected between the beginning of September 2019 and the end of February 2020 over a six-month period.

\section{- Statistical analysis}

- The data obtained was tabulated using the SPSS version and statistically analyzed (20). When p-value 0.05, and high significance when $\mathrm{p}$-value 0.001 and no statistically significant difference when $\mathrm{p}$-value $>0.05$ is considered, statistical significance difference was considered. Statistical tests were used, including an independent t-test and a Chi-square test.

\section{- Results}

Table (1) shows that $40 \%$ \& $50 \%$ of participants in the urban and rural group respectively were in the age group from 18-25 years with mean age \pm SD $28.82 \pm 5$ and $25.62 \pm 5$ respectively. As regards the educational level $50 \%$ and $55 \%$ of both groups were had secondary school. Half of the participants $50 \%$ and $45 \%$ had an income from 1500 to 3000 bound per month in the urban and rural groups respectively. Also, the table reveals that $63 \%$ and $50 \%$ of both groups were employees.

- Table (2) clarifies that $40 \%$ and $50 \%$ of participants in the urban and rural groups respectively were of gestational age between 20-24 weeks. $65 \%$ and $70 \%$ of urban and rural groups of women respectively were multigravida. Also $25 \%$ of both groups had one parity. $63 \%$ and $75 \%$ of the urban and rural groups respectively didn't have a premature baby. The table also revealed that $70 \%$ and $80 \%$ of both groups have no history of familial diabetes.

- Figure (1) reveals that before the implementation of education sessions the total score of knowledge regarding gestational diabetes for both urban and rural group was $65.2 \%$ and $70.5 \%$ respectively have a poor level of knowledge, this improved in both groups after implementation of education were $70 \%$ and $62 \%$ of the urban and rural group respectively have a good level of knowledge. 
Figure (2) illustrates that before the implementation of educational sessions total lifestyle score for both urban and rural group were $82 \%$ and $80 \%$ respectively have an unhealthy lifestyle, this improved in both groups after implementation of education were $75 \%$ and $78 \%$ of the urban and rural group respectively have a healthy lifestyle.

Table (3) shows that there was no statistically significant difference in all women's lifestyle elements regarding GDM before the execution of GDM educational sessions in both urban and rural groups (nutrition, physical activity, stress management, health responsibility, spiritual growth, and interpersonal relations). Otherwise, four weeks after providing GDM educational sessions in both urban and rural groups, the table shows that all women's lifestyle items have improved in terms of GDM (nutrition, physical activity, stress management, health responsibility, spiritual growth, and interpersonal relations). Also, there was a slightly statistically significant difference in the rural group's best interest in diet, and there was a slightly statistically significant difference in physical activity for the urban group.

Table (4) indicates that about healthy lifestyle: nutrition (irregular food schedules, irregular working, and sleeping times) and (some cultures encourage eating large quantities in pregnancy) were the most factors $40 \%$ and $100 \%$ which negatively affecting on compliance to health education instructions among urban and rural group respectively. According to physical activity (Insufficient time for sports due to work and children) and (lack of suitable places for walking \& family does not accept to go out for a daily walk) were the most factors $60 \%$ and $42.8 \%$ which negatively affecting on compliance to health education instructions among urban and rural groups respectively. Regarding stress management, health responsibility, spiritual growth and interpersonal relations (the family is not helping in implement program instructions and have no time to get enough sleep and relaxation each day because of work and children) and (Not every problem you meet requires a professional doctor's advice, and can take advice from family and friends) and (I cannot expect the best in the future because of fear) and (I think that people close to me have no idea about my fear and problems). These were the most factors $50 \%$ and $100 \%$ affecting negatively on compliance to health education instructions among both urban and rural group respectively.

Table (5) as shown in the table, among the urban group there was a significant fair 
association between total awareness scores and total lifestyle scores before GDM educational sessions $(r=0.37, p=0.02)$. After the implementation of the program, there was a significant strong association between the two scores, $(\mathrm{r}=0.82, \mathrm{p}=$ 0.006). However, among the rural group, there was no association between total lifestyle score and total awareness score before the program, but there was a moderate association between the two scores, $(r=0.71, p=0.01)$ was found four weeks after execution of GDM educational sessions. 
Table (1): Distribution of the participants according to their socio demographic characteristics $(\mathrm{N}=\mathbf{8 0})$

\begin{tabular}{|c|c|c|c|c|c|c|}
\hline \multirow{2}{*}{$\begin{array}{l}\text { Demographic } \\
\text { characteristics }\end{array}$} & \multicolumn{2}{|c|}{ Urban group (40) } & \multicolumn{2}{|c|}{ Rural group (40) } & \multirow[t]{2}{*}{$\mathbf{X}^{2}$} & \multirow[t]{2}{*}{$\mathbf{p}$} \\
\hline & No & $\%$ & No & $\%$ & & \\
\hline \multicolumn{7}{|l|}{ Age } \\
\hline $18-25$ years & 16 & 40 & 20 & 50 & \multirow{4}{*}{1.7} & \multirow{4}{*}{0.45} \\
\hline$>25-35$ years & 14 & 35 & 12 & 30 & & \\
\hline$>35-45$ years & 10 & 25 & 8 & 20 & & \\
\hline Mean \pm SD & \multicolumn{2}{|c|}{$28.82 \pm 5$} & \multicolumn{2}{|c|}{$25.62 \pm 5$} & & \\
\hline \multicolumn{7}{|l|}{ Level of Education } \\
\hline Illiterate & 8 & 20 & 10 & 25 & 0.24 & 0.1 \\
\hline Secondary School & 20 & 50 & 22 & 55 & & \\
\hline \multicolumn{7}{|l|}{ Income } \\
\hline Less than $1500 \mathrm{~L} /$ month & 12 & 30 & 16 & 40 & 0.12 & \multirow{4}{*}{0.1} \\
\hline From 1500 to 3000 & 20 & 50 & 18 & 45 & & \\
\hline $\mathrm{L} / \mathrm{month}$ & 8 & 20 & 6 & 15 & & \\
\hline More than3000L/month & & & & & & \\
\hline \multicolumn{7}{|l|}{ Occupation } \\
\hline Housewife & 15 & 37 & 20 & 50 & 1.4 & 0.010 \\
\hline Employed & 25 & 63 & 20 & 50 & & \\
\hline
\end{tabular}

$\mathrm{SD}=$ Standard Deviation.Chi-Square test for $\mathrm{p}$ value 
Table (2): Frequency distribution of studied sample regarding obstetric history $(n=80)$

\begin{tabular}{|c|c|c|c|c|c|c|}
\hline \multirow{2}{*}{ Items } & \multicolumn{2}{|c|}{ Urban group (40) } & \multicolumn{2}{|c|}{ Rural group (40) } & \multirow[t]{3}{*}{$\overline{X^{2}}$} & \multirow[t]{3}{*}{$\overline{\overline{\mathbf{P}}}$} \\
\hline & No & $\%$ & No & $\%$ & & \\
\hline \multicolumn{5}{|c|}{\begin{tabular}{|l|} 
Gestational age / weeks \\
\end{tabular}} & & \\
\hline $\begin{array}{l}20-24 \\
25-28 \\
>28\end{array}$ & $\begin{array}{l}16 \\
14 \\
10\end{array}$ & $\begin{array}{l}40 \\
35 \\
25\end{array}$ & $\begin{array}{c}20 \\
12 \\
8\end{array}$ & $\begin{array}{l}50 \\
30 \\
20\end{array}$ & 2.37 & 0.45 \\
\hline \multicolumn{7}{|l|}{\begin{tabular}{|l|} 
Gravida \\
\end{tabular}} \\
\hline $\begin{array}{l}\text { Primigravida } \\
\text { Multigravida }\end{array}$ & $\begin{array}{l}14 \\
26\end{array}$ & $\begin{array}{l}35 \\
65\end{array}$ & $\begin{array}{l}10 \\
30\end{array}$ & $\begin{array}{l}30 \\
70\end{array}$ & 0.17 & 0.45 \\
\hline \multicolumn{7}{|l|}{ parity } \\
\hline $\begin{array}{l}0 \\
1 \\
2 \\
\text { Three or More }\end{array}$ & $\begin{array}{c}14 \\
10 \\
10 \\
6\end{array}$ & $\begin{array}{l}35 \\
25 \\
25 \\
15\end{array}$ & $\begin{array}{l}10 \\
10 \\
10 \\
10\end{array}$ & $\begin{array}{l}25 \\
25 \\
25 \\
25\end{array}$ & 1.24 & 0.93 \\
\hline \multicolumn{7}{|c|}{ Have a premature baby } \\
\hline \begin{tabular}{|l|} 
Yes \\
No \\
\end{tabular} & $\begin{array}{l}15 \\
25 \\
\end{array}$ & $\begin{array}{l}37 \\
63 \\
\end{array}$ & $\begin{array}{l}10 \\
30 \\
\end{array}$ & $\begin{array}{l}25 \\
75 \\
\end{array}$ & 1.43 & 0.82 \\
\hline \multicolumn{7}{|c|}{ Having familial diabetes } \\
\hline $\begin{array}{l}\text { Yes } \\
\text { No } \\
\end{array}$ & $\begin{array}{l}12 \\
28 \\
\end{array}$ & $\begin{array}{l}30 \\
70 \\
\end{array}$ & $\begin{array}{c}8 \\
32 \\
\end{array}$ & $\begin{array}{l}20 \\
80 \\
\end{array}$ & 0.22 & 0.24 \\
\hline
\end{tabular}

Chi-Square test for $\mathrm{p}$ value.

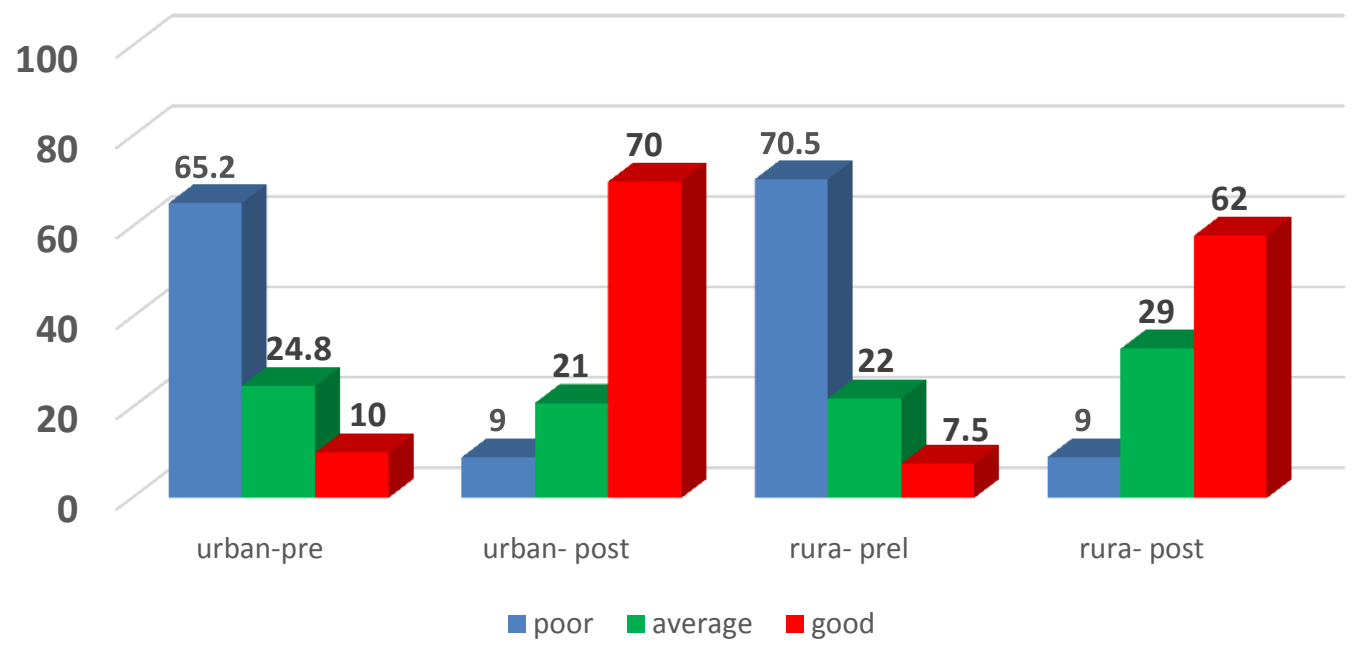

Fig.1: Frequency distribution of studied sample' total knowledge score regarding gestational diabetes before and four weeks after GDM educational sessions implementation. 


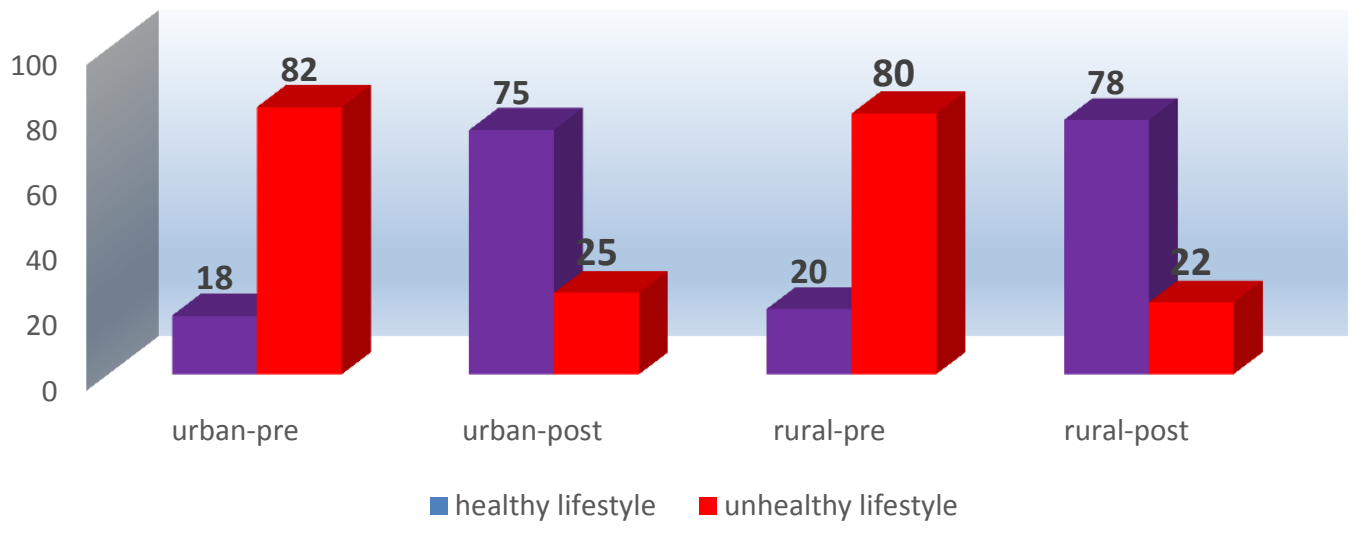

Fig(2):Frequency distribution of studied sample regarding total lifestyle score before and four weeks after GDM educational sessions implementation $(\mathbf{n = 8 0})$

Table (3):Comparison of lifestyles' mean-scores of studied groups before and four weeks after GDM educational sessions implementation $(n=80)$

\begin{tabular}{|c|c|c|c|c|c|c|c|c|}
\hline \multirow[t]{3}{*}{$\begin{array}{c}\text { Lifestyle } \\
\text { Items }\end{array}$} & \multicolumn{2}{|c|}{$\begin{array}{c}\text { Before GDM educational } \\
\text { sessions } \\
\text { implementation }\end{array}$} & \multirow[t]{3}{*}{$\mathbf{X}^{2}$} & \multirow[t]{3}{*}{$\mathbf{P}$} & \multicolumn{2}{|c|}{$\begin{array}{c}\text { weeks after GDM educational } \\
\text { sessions } \\
\text { Implementation }\end{array}$} & \multirow[t]{3}{*}{$\mathbf{X}^{2}$} & \multirow[t]{3}{*}{$\mathbf{P}$} \\
\hline & Urban $=40$ & Rural $=40$ & & & Urban $=40$ & Rural $=40$ & & \\
\hline & $\mathrm{M}(\mathrm{SD})$ & $\mathrm{M}(\mathrm{SD})$ & & & $\mathrm{M}(\mathrm{SD})$ & $\mathrm{M}(\mathrm{SD})$ & & \\
\hline \multicolumn{9}{|c|}{ Nutrition } \\
\hline & $44.70 \pm 3.74$ & $45.64 \pm 2.71$ & 1.45 & 0.34 & $69.05 \pm 8.61$ & $75.13 \pm 9.21$ & 2.14 & $\begin{array}{c}0.0 \\
51 \\
*\end{array}$ \\
\hline \multicolumn{9}{|c|}{ Physical activity } \\
\hline & $20.07 \pm 5.52$ & $19.75 \pm 6.88$ & 1.12 & 0.41 & $44.96 \pm 1.31$ & $36.62 \pm 1.52$ & 1.54 & $\begin{array}{l}0.0 \\
02 \\
*\end{array}$ \\
\hline \multicolumn{9}{|c|}{ Stress management } \\
\hline & $21.51 \pm 2.50$ & $19.33 \pm 1.57$ & 1.32 & 0.21 & $33.95 \pm 2.42$ & $31.65 \pm 2.51$ & 1.25 & $\begin{array}{l}0.2 \\
3\end{array}$ \\
\hline \multicolumn{9}{|c|}{ Health responsibility } \\
\hline & $\begin{array}{c}31.90 \pm 11.4 \\
8\end{array}$ & $30.87 \pm 7.54$ & 1.16 & 0.25 & $62.21 \pm 9.41$ & $61.53 \pm 5.56$ & 4.52 & $\begin{array}{l}0.5 \\
4\end{array}$ \\
\hline \multicolumn{9}{|c|}{ Spiritual Growth } \\
\hline & $\begin{array}{c}35.75 \pm 14.6 \\
2\end{array}$ & $33.88 \pm 15.22$ & 1.02 & 0.32 & $61.58 \pm 8.530$ & $61.83 \pm 9.668$ & 1.28 & $\begin{array}{l}0.3 \\
5 \\
\end{array}$ \\
\hline \multicolumn{9}{|c|}{ Interpersonal relations } \\
\hline & $\begin{array}{c}33.57 \pm 11.4 \\
4\end{array}$ & $32.27 \pm 13.12$ & 1.53 & 0.24 & $51.57 \pm 10.46$ & $52.27 \pm 11.16$ & 1.54 & $\begin{array}{l}0.2 \\
6\end{array}$ \\
\hline
\end{tabular}

Chi-Square test for $\mathrm{p}$ value. 
Table (4): Frequency distribution of barriers affecting compliance to health education instructions regarding their lifestyle among the study sample

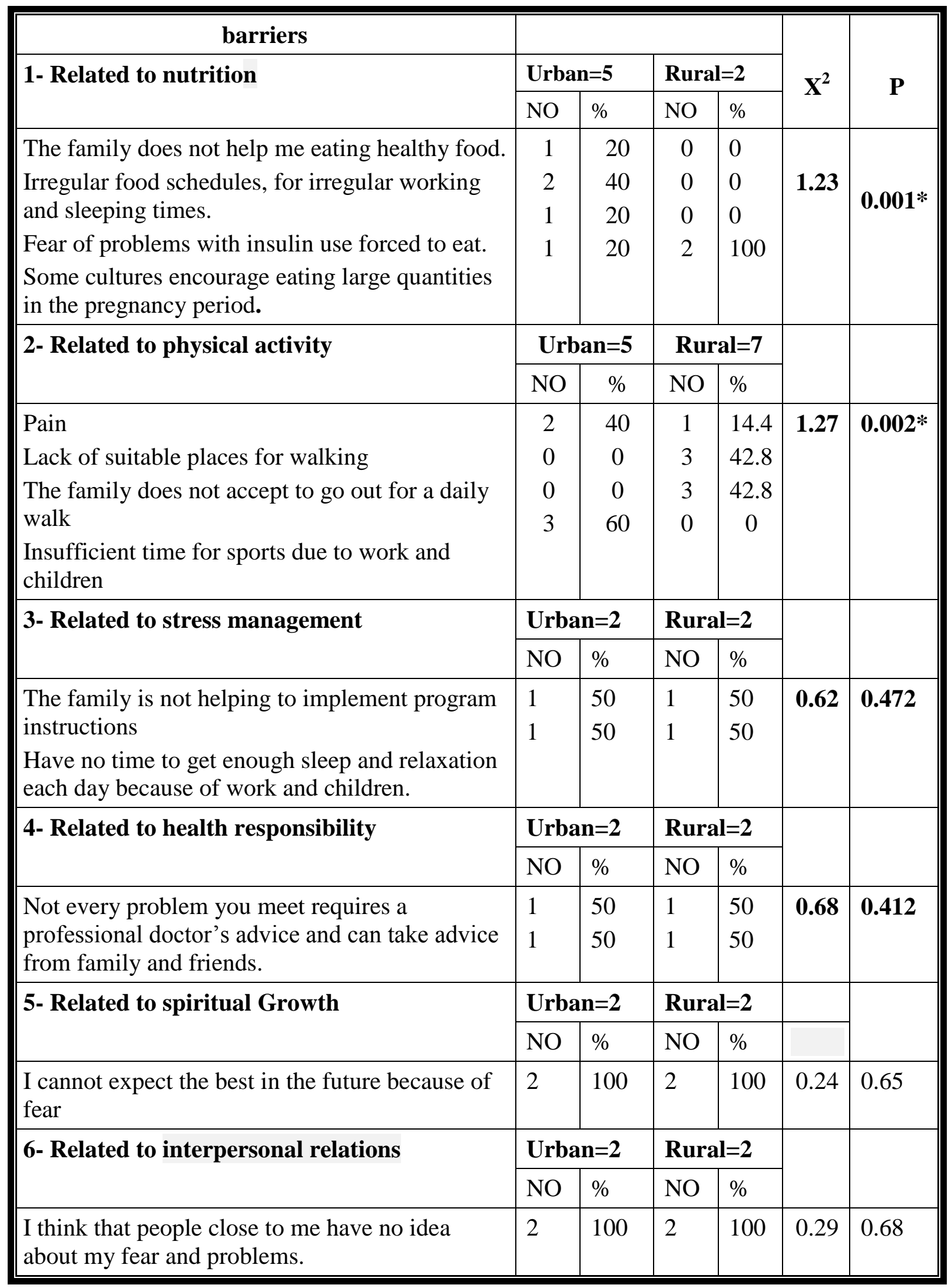

( $N=$ only who didn't comply with health education instructions). Fisher's Exact test 
Table (5): Association between total score of knowledge and lifestyle among both groups before and 4 weeks after GDM educational sessions implementation $(n=80)$

\begin{tabular}{|l|l|l|l|l|}
\hline \multirow{2}{*}{ lifestyle score } & \multicolumn{2}{|c|}{ Urban Group $(\mathrm{n}=40)$} & \multicolumn{2}{c|}{ Rural Group $(\mathrm{n}=40)$} \\
\cline { 2 - 5 } \multicolumn{1}{c|}{ Knowledge score } & \multicolumn{1}{|c|}{$\begin{array}{c}\text { Before } \\
\text { program }\end{array}$} & $\begin{array}{c}\text { After } \\
\text { program }\end{array}$ & $\begin{array}{c}\text { Before } \\
\text { program }\end{array}$ & $\begin{array}{c}\text { After } \\
\text { program }\end{array}$ \\
\hline $\mathrm{R}$ & 0.37 & 0.82 & 0.41 & 0.71 \\
\hline $\mathrm{P}$ value & 0.02 & $0.006^{*}$ & 0.12 & $0.010^{*}$ \\
\hline
\end{tabular}




\section{Discussion}

Diabetes mellitus is considered to be a major community health issue linked to severe morbidity, mortality, use of health services, and costs, it is associated with potentially adverse effects on both mother and fetus, which can significantly jeopardize the mothers and fetus' health.The present study aims to evaluate "the effect of educational sessions on improving knowledge and lifestyle among rural versus urban gestational diabetic women".

Table (1) showed socio-demographic characteristics of the studied sample, which revealed that more than one third in urban and half of the participants in rural groups were in the age group from 18-25 yrs. with Mean age \pm SD 28. $82 \pm 5$ and 25.62. \pm 5 yrs. respectively. These results agreed with those of Javid etal.,2015 ${ }^{(\mathbf{1 6})}$ who compared the lifestyles of women with gestational diabetes and healthy pregnant women and concluded that the mean age was $27.8 \pm 4.56$ and $28.68 \pm$ 3.83 years for both the control and study group. As regards educational level half of urban participants and more than half of rural participants were had secondary school. This result doesn't match with Alharthi etal.,2018 ${ }^{(17)}$ who reported that most of their study participants had bachelor's degrees or higher.
Table (2) clarified that more than one-third of participants in the urban and half of participants in the rural group were in gestational age between 20-24 weeks and more than two-thirds of both groups were multigravida. Also, one-quarter of both groups respectively had one parity. Nearly two-thirds and three-quarters of both groups in order urban and rural haven't a premature baby. This came in accordance with Zandinava etal.,2017 ${ }^{(\mathbf{1 8})}$ who reported that around half of women (40 percent) reported having two pregnancies and threequarters (71 percent) had a living child.

Concerning total knowledge scores about gestational diabetes Figure (1), the present study revealed that nearly two thirds and less than three quarters respectively have a poor level of knowledge, which improved in both groups after implementation of educational sessions to become nearly three quarters and nearly two-thirds of urban and rural group respectively have a good level of knowledge. This improvement is very valuable because the gain of accurate knowledge is considered the cornerstone for and linked to a healthy lifestyle, but the women need more followup to change their lifestyle. This came in accordance with Kaveh etal.,2012 ${ }^{(19)}$ who indicated that after the training 
intervention, the average level of knowledge increased significantly.

Also, these results agreed with Mohammed et al.,2016 ${ }^{(\mathbf{2 0 )}}$ who found that approximately three quarters of gestational diabetic women had insufficient knowledge with a score (09) before attending the planned structurededucational program, while almost one-quarter of them had a moderate adequate level of knowledge with a score (10-18), and a small proportion of them had adequate knowledge with a score (19-27). After attending the program, around half of the gestational diabetic women had adequate and moderate levels of awareness. From the researcher'spoint of view, this may be rendered to lack of spreading awareness about the nature of GDM and how to deal with it through mass media such as T.Vand thus improving the lifestyle to eliminate potential risks. These results also came at the same line with Morrison etal.,2014 ${ }^{(21)}$ who stressed the importance of help from health practitioners to provide insight into the obstacles and opportunities for reducing the likelihood of potential diabetes.

In relation to Figure (2) which illustrated total lifestyle scores before and four weeks after GDM educational sessions implementation, it was found that total lifestyle scores for the majority of both urban and rural groups have unhealthy lifestyle before the implementation of educational sessions, while after implementation of the educational sessions, more than three-quarters of both urban and rural groups have a healthy lifestyle. These results support the results of Said etal.,2019 ${ }^{(22)}$ who found that less than half of both control and intervention groups had a healthy lifestyle level towards GDM before the introduction of GDM educational sessions, compared to almost half of the control group, and four weeks after the implementation of GDM educational sessions, the majority of the intervention group had a healthy lifestyle level towards GDM. This may be due to insufficient awareness of GDM before the application of educational sessions, which subsequently leads to unhealthy lifestyle.

Table (3) show that in both urban and rural groups and before implementation of the GDM educational package there was no statistically significant difference about all items of women's lifestyle regarding GDM (nutrition, physical exercise, stress management, health responsibility, spiritual growth, and interpersonal communications). Otherwise, four weeks after GDM educational package implementation in both urban and rural groups the table indicates that there was significant improvement regardingthe same items of women's lifestyle suffering 
from GDM.These results came in the same line with the study ofSaid etal.,2019 ${ }^{(22)}$ where the researcher found that there was a high statistically significant difference in gestational diabetes with respect to all aspects of women's lifestyle (nutrition, physical activity, control of stress and health responsibility) $(\mathrm{P}<0.001)$. Because of the high level of compliance with the education program among women, these results can be interpreted.

These findings were also agreed with Gamboa etal.,2013 ${ }^{(23)}$ who concluded that through educational programs, continuous supervision and raising awareness will encourage habits such as exercise, healthy diet, etc., and thus improve the disease. Also, these results came in accordance with Amy etal.,2014 ${ }^{(24)}$ and reported that quick adaptation to dietary management in a short time created challenges for women with GDM. Stress and anxiety were reported when women talked about following dietary advice. Tailored educational consultation with consideration of the barriers may promote dietary compliance and overall better health.

And agreed with Pour etal.,2013 ${ }^{(25)}$ who showed after two months of completion of the intervention, the beneficial impact of the self-care instructional program on the quality of life in the intervention population was shown. From the researchers' point of view, these findings result from discussing with the pregnant woman different ways to improve their lifestyle such as exercises that could be carried out and providing alternatives such as walking when some restrictions about some exercises were found.

In relation to factors affecting compliance to health education instructions regarding their lifestyle among the studied sample, findings of the present study showed that the most common factors related to nutrition are (irregular food schedules, irregular working and sleeping times) and (some cultures encourage eating large quantities during pregnancy), regarding physical activity, (insufficient time for sports due to work and children) and (lack of suitable places for walking and family does not accept to go out for a daily walk) were the most factors. These findings were in the same line with Mukona et al.,2017 ${ }^{(26)}$ who found that low socioeconomic status, lack of family, peer and community support, consequences of pregnancy, complicated therapeutic regimens, diabetes pathophysiology, cultural and religious values, and poor health care system were found to be obstacles. We may rationalize these results because during pregnancy there is an idea 
that the pregnant woman should eat well in order to get a healthy baby and some cultures even limit some kinds of exercises that could interfere with practicing it.

The current research showed that before and four weeks after the introduction of GDM educational sessions, there was a strong statistically meaningful association between total awareness scores and total lifestyle scores in both urban and rural communities. These results were in accordance with Sen etal.,2015 ${ }^{(27)}$ who proved that the educational approach has been shown to have the ability to enhance the quality of life of women with GDM.

These results also supported with Said et al.,2019 $^{(22)}$ in which it was found that a statistically significant positive association existed between the total lifestyle score and the total information score. This may be due to the need for consistent women's education, using a range of educational models, as an integral component of the diabetes care program that can contribute tothe desired change in women's lifestyle.

\section{Conclusion}

The application of health education sessions play an important role in improving the knowledge, and lifestyle among gestational diabetic women in rural and urban regions.

\section{Recommendations}

- Provide a continuous planned educational program and offered on regular basis for both urban and rural groups of women with gestational diabetes to improve their knowledge, and the lifestyle and associated morbidity.

- Attempting to remove barriers faced by pregnant women with gestational diabetes to comply with the instructions of the educational program, by integrating the partners, family members, and peers in the educational sessions and increasing the open places and promoting a culture of physical activities for women especially in a rural area to achieve long-term lifestyle change.

- Raising awareness of changing the unhealthy lifestyle for women before marriage and during pregnancy planning.

- Applying health education about gestational diabetes on a large sample in different settings to enhance and confirm the current results.

\section{References}

1. Koning $\mathrm{SH}$, Hoogenberg $\mathrm{K}$, Lutgers HL, Van den Berg PP, Wolffenbuttel BH. Gestational Diabetes Mellitus. Current knowledge and unmet needs. Journal of Diabetes. 2016; 8(6): 770-81. 
2. Zhu WW, Yang HX, Wang C, Su RN, Feng H, KapurA. High prevalence of gestational diabetes mellitus in Beijing. Effect of maternal birth weight and other risk factors. Chinese Medical Journal. 2017; 130(9): 1019-25.

3. Khiyali Z, Manoochri M, Khani A, BabaeiHeydarabadi, A,Mobasheri F. Educational intervention on preventive behaviors on gestational diabetes in pregnant women. Application of health belief model. International Journal of Pediatrics. 2017; 5(5): 4821-31.

4. Billionnet C, Mitanchez D, Weill A, Nizard J, Alla F, Hartemann A, et al. Gestational diabetes and adverse perinatal outcomes from 716,152 births in France in 2012. Diabetologia. 2017; 60 (4): 636-44.

5. Whincup PH, Kaye S, Owen CG, Huxley R, Cook DG., Anazawa S, et al. Birth weight and risk of type 2 diabetes. A quantitative systematic review of published evidence. Journal of Epidemiology and Community Health. 2008; 300 (24): 2886-97.

6. Muhwava LS, Murphy K, Zarowsky C, Levitt N. Experiences of lifestyle change among women with gestational diabetes mellitus (GDM). Abehavioral diagnosis using the COM-B model in a low-income setting. PloS. one, 2019; 14(11): 1-21.
7. Sedighi S, Akbari SA, Afrakhteh M, Esteki T, Majd HA, Mahmoodi Z. Comparison of lifestyle in women with polycystic ovary syndrome and healthy women. Global Journal of Health Science. 2015; 7(1): 228-34.

8. Nankervis A,Conn J. Gestational diabetes mellitus. Negotiating the confusion. Australian Family Physician. 2013; 42(8): 528-31.

9. World Health Organization. Diagnostic criteria and classification of hyperglycemia first detected in pregnancy (2013). Available at:http://apps.who.int/iris/bitstream/106 65/85975/1/WHO_NMH_MND_13.2_e ng.pdf, Accessedat:20 Apr. 2015.

10. Azzam HF, El Sharkawy NB. Effect of Gestational Diabetes Mellitus Health Education Module on pregnancy outcomes. World Journal of Nursing Sciences. 2015; 1 (3): 76-88.

11. Bone RL. Big Babies. An exploration of gestational diabetes. International Journal of Childbirth Education. 2015; 3 (30): 5- 42.

12. Cunningham FG. Williams Obstetrics.24 $4^{\text {th }}$ Ed. New York: MC Graw Hill; 2014. 25-43.

13. El Sagheer MG, Hamid L. Prevalence and risk factors for gestational diabetes mellitus according to diabetes in pregnancy studied group in comparison 
to international association of the diabetes. The Egyptian Journal of Internal Medicine. 2018; 30 (3): 131-39.

14. Afefy N. Effect of structured educational session about gestational diabetes on maternity nurse's knowledge at selected primary health care hospitals, Egypt. Journal of Education and Practice. 2017; 17(8): $56-62$.

15. University of Nebraska College of Nursing. Health Promoting Lifestyle Profile II. Retrieved September 29, 2010.

Availableat:http://www.unmc.edu/nursi ng/Health_Promoting_Lifestyle_Profile _II.htm 2010.

16. Javid FM, Simbar M, Dolatian M, Majd HA. Comparison of lifestyles of women with gestational diabetes and healthy pregnant women. Global Journal of Health Science. 2015; 7(2): 162-69.

17. Alharthi AS, Althobaiti KA, Alswat KA. Gestational diabetes mellitus knowledge assessment among Saudi women. Open access Macedonian Journal of Medical Sciences. 2018; 6(8): 1522-28.

18. Zandinava H, Shafaei FS, Charandabi SM, Homayi SG, Mirghafourv M. Effect of educational package on selfcare behavior, quality of life, and blood glucose levels in pregnant women with gestational diabetes. A randomized controlled trial. Iranian Red Crescent Medical Journal. e44317. 2017 April; 19(4): 1-9.

19. Kaveh MH, Kiani A, Salehi M, Amouei S. Impact of education on nutrition and exercise on the level of knowledge and metabolic control indicators (FBS \& PPBS) of gestational diabetes mellitus (GDM) patients. Iranian Journal of Endocrinology and Metabolism. 2012; 13 (5): 441-48.

20. Mohammed GA, Eswi A, Fahmy H, Shehata HM. Impact of designed teaching program for pregnant women with gestational diabetes on maternal outcomes. Journal of Health, Medicine and Nursing. 2016;33(2): 30-39.

21. Morrison MK, Lowe JM, Collins CE. Australian women's experiences of living with gestational diabetes. Women and Birth Journal. 2014; 27(1): 52-57.

22. Said AR, Aly FK. Effect of the educational sessions based on health Belief Model regarding lifestyle among women with gestational diabetes mellitus. International Journal of Nursing Science. 2019; 11(2): 41-52.

23. Gamboa ME, Sanchez PA, VrotsouK, Arbonies OJ, Del CampoPena E, Ochoa G. Impact of a self-care education programme on patients with type 2 diabetes in primary care in the Basque 
Country. BMC Public Health. 2013; 13

(1): $1-8$.

24. Amy LH, Gustaaf S, Dexter $H$, Elizabeth S. Barriers and coping strategies of women with gestational diabetes to follow dietary advice. Women and Birth Journal home page. www.elsevier.com. 2014; (27): 292-97.

25. Pour JS, Jafari M, Asgar MG, Dardashti HD, Teymoorzadeh E. The impact of self-care education on life quality of diabetic patients. Journal of Health Administeration. 2013; 16 (52): 26-36.

26. Mukona D, Munjanja SP, Zvinavashe M, Stray-Pederson B. Barriers of adherence and possible solutions to non-adherence to anti diabetic therapy in women with diabetes in pregnancy. Patient's perspective. Journal of Diabetes Research. 2017; (2017): 1-10.

27. Sen E, Sirin A. Healthy lifestyle behaviors and self-efficacy. The effect of education. Anthropologist. 2015; 21(1-2): 89-97. 